Available online on 15.06.2020 at http://jddtonline.info
Open Access to Pharmaceutical and Medical Research
unrestricted non-commercial use, provided the original work is properly cited

Open 2 Access

Research Article

\title{
Formulation, Characterization and Antihelminthic Activity Testing of Nitazoxanide Superporous Hydrogel Tablets
}

\author{
S. Vinaya Srikala*1, Nagam Santhi Priya ${ }^{2}$, Rama Rao Nadendla ${ }^{3}$ \\ ${ }^{1}$ M.Pharmacy, Department of pharmaceutics, Chalapathi Institute of Pharmaceutical Sciences, Lam, Guntur - 522034, Andhra Pradesh, India \\ ${ }^{2}$ Assistant Professor, Department of pharmaceutics, Chalapathi Institute of Pharmaceutical Sciences, Lam, Guntur - 522034, Andhra Pradesh \\ India \\ ${ }^{3}$ Professor and Principal, Department of pharmaceutics, Chalapathi Institute of Pharmaceutical Sciences, Lam, Guntur - 522034, Andhra \\ Pradesh, India
}

\begin{abstract}
In the pharmaceutical field controlled release products have the ability to maintain desired medicament concentration or a longer period of time. Certain drugs are relatively insoluble in water and have high dose requirements that render unsuitable formulation difficulties in sustained release formulations. Nitazoxanide which is a high dose water insoluble antiprotozoal drug was formulated with the aim. To modulate gastro-retentive dosage form based on the superporous hydrogel composites. Foaming technique was used in the preparation of SPH composites. The superporous hydrogels were extremely sensitive to $\mathrm{pH}$ of swelling media and good porosity. Superporous hydroge ls tablets of nitazoxanide showed good pre-compressional and post-compressional properties. Formulation $\mathrm{X}$ is the best formulation containing chitosan, polyvinyl alcohol, formaldehyde, exhibited good swelling ratio. The compatibility studies were performed by Fourier Transform Infrared (FTIR) Spectroscopic Studies, Differential Scanning Calorimetry Studies (DSC). All formulations were evaluated for stability, drug content, and kinetic drug release \& in-vitro drug release profile. It was concluded that the proposed gastro-retention drug delivery provides a different supply of nitazoxanide directly to the stomach.
\end{abstract}

Keywords: Nitazoxanide, Anti protozoal, foaming technique, Chitosan

Article Info: Received 21 March 2020; Review Completed 28 April 2020; Accepted 11 May 2020; Available online 15 June 2020

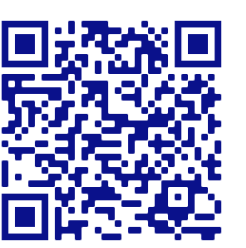

Cite this article as:

Srikala SV, Santhi Priya N, Nadendla RR, Formulation, Characterization and Antihelminthic Activity Testing of Nitazoxanide Superporous Hydrogel Tablets, Journal of Drug Delivery and Therapeutics. 2020; 10(3-s):26-36 http://dx.doi.org/10.22270/jddt.v10i3-s.4130

Nagam Santhi Priya, Assistant professor, Department of pharmaceutics, Chalapathi institute of pharmaceutical sciences, Lam, G untur, Andhra Pradesh, India

\section{INTRODUCTION}

Hydrogels are hydrophilic, cross linked polymers which are able to absorb large amounts of water and remain water in soluble all though slow swelling is beneficial their arises situations where a fast swelling polymer is more desirable therefore a new generation of hydrogels ${ }^{1}$. Which swell and absorb water rapidly has been developed and is termed as superporous hydrogels which swell to an extent of uniform and equilibrium size in a short span of time. The synthesis involves either cross linking of monomers using multifunctional cross linking agent usually by polymerization and gas blowing technique or copolymerization by using chemical compounds/ irradiation ${ }^{2}$. For drug delivery applications conventional hydrogels is limited due to slow swelling kinetics. Improvement of swelling rate is possible by making hydrogel porous or superporous. The word superporous means the pore structure of the hydrogel is open and connected. In this way the water will be absorbed into the hydrogel structure by means of diffusion and capillary actions. The draw back here is the more porous the structure is the weaker the hydrogel structure so to improve mechanical properties foaming and gelation process are used to improve compressive strength, elasticity ${ }^{3}$.

Nitazoxanide is an antihelminthic and antiprotozoal agent having broad spectrum of activity. It is chemically 2acetyloxy (N-(5-nitro-2thiazolyl) benzamide. Nitazoxanide is a light yellow crystalline powder which is insoluble in water and poorly soluble in ethanol. It belongs to BCS class II drug in biopharmaceutical classification system i.e. low solubility and high permeability. It is used for treating diarrhea caused 
by Giardia lambila as well as for cryptosporidiosis in immune-compromised patient ${ }^{4}$.

The pharmaceutical composition of tablet dosage form comprises of a first portion of nitazoxanide in a controlled release manner and second portion with second quantity of nitazoxanide for immediate release effect here the control release property is assumed where in absorption and bioavailability of the active agent over extended period of time and also the immediate release portion of the active agent is made bio available without substantial delay. In the present research work $2^{3}$ full factorial design i.e. 3 factors and 2 levels was used to optimize the concentrations of chitosan, polyvinyl alcohol, microcrystalline cellulose and response is cumulative \% drug release by using DesignExpert software.

\section{MATERIALS AND METHODS}

\section{Materials}

Chitosan, Poly vinyl alcohol (PVA), Formaldehyde and Sodium bicarbonate, microcrystalline cellulose, magnesium stearate, talc were obtained by Chalapathi institute of pharmaceutical sciences, lam, Guntur. Nitazoxanide is a kind gift sample from pellets pharma limited.

\section{Methods}

Preparation of nitazoxanide loaded Superporous Hydrogels

Chitosan is dissolved in $0.1 \mathrm{M}$ acetic acid solution to obtain $2 \% \mathrm{w} / \mathrm{v}$. A $10 \% \mathrm{w} / \mathrm{v}$ aqueous solution of PVA was prepared. The chitosan solution was dispersed in PVA solution and homogenized for 15 minutes definite composition of formaldehyde was added as crosslinking agent. Calculated quantities of sodium bicarbonate was added and homogenized for a period of 4hours in ultraterax to induce uniform gelation, crosslinking and effervescent reactions. The swelled and formed hydrogels were left to stand overnight at room temperature. The hydrogels were freeze dried for 12 hours. The freeze dried samples were stored in well closed container. (Table no.1)

\section{Formulation of SPH tablets of nitazoxanide}

$500 \mathrm{mg}$ drug equivalent superporous hydrogel microcrystalline cellulose were weighed accurately were taken in a poly bag and blended by shaking for 10 minutes. To the powder blend magnesium stearate, talc, sodium bicarbonate were added and were mixed for 5 more minutes by shaking to ensure complete mixing. The powder blend is passed through 80 sieve and were compressed into tablets. (Table no.2)

\section{Anthelmintic activity in Pheretima posthuma}

Collection of Pheretima posthuma: Pheretima posthuma were collected from the swampy water along with amaravathi road, Chalapathi institute of Pharmaceutical Sciences, lam, Guntur, Andhra Pradesh, India. The average size of worms was $5-9 \mathrm{~cm}$.

Preparation of drug solutions: The standard drug metronidazole was received from chalapathi institute of pharmaceutical sciences and test samples were synthesized in chalapathi drug testing laboratory, chalapathi institute of pharmaceutical sciences. Metronidazole and test samples were prepared as Group-I is contains saline $0.9 \% \mathrm{Nacl}$ in water), Group-II is containing metronidazole as a reference standard $(400 \mathrm{mg} / \mathrm{ml})$, Group-III containing NSPH-I (nitazoxanide loaded superporous hydrogel) $(200 \mathrm{mg} / \mathrm{ml})$, Group-IV containing NSPH-II $(400 \mathrm{mg} / \mathrm{ml})$.

\section{Optimization by $2^{3}$ Factorial Designs}

The $2^{3}$ full factorial designs were carried out systematically with 3 factors at 2 levels to prepare the nitazoxanide loaded SPH tablets. A total of 8 experimental trials were done at all possible combinations. During optimization of excipient the amount of chitosan, Polyvinyl alcohol, Microcrystalline cellulose and response is cumulative \% drug release were selected as the independent variables that were varied at 2 levels i.e. low and high. (Table 3)

\section{RESULTS AND DISCUSSIONS}

\section{Characterization of superporous hydrogels}

The following parameters are suitable for superporous hydrogels

Physical Appearance: Clarity, color, and presence of any particles were examined visually in the prepared hydrogels.

Percent Yield of SPH: The percent yield represents the amount of material produced after SPH freezing, compared with the amount retained for freeze drying. The formula can be calculated by,

$$
\text { Percentage yield }=\frac{\text { Weight of sample after drying }}{\text { Weight of sample before drying }} \times 100
$$

Drug content of SPH: Superporous hydrogel drug content was calculated to assess how much of a particular amount of superporous hydrogel is present. We taken in $100 \mathrm{ml}$ volumetric flask, a superporous hydrogel required was taken. After that $10 \mathrm{ml}$ of buffer was added, mixed well and make upto volume. The above mixture was filtered, and drug content determined by using correct wavelength of a UV visible spectrophotometer 5 .

Gelatin Kinetics: The reaction to polymerization continues to increase the viscosity until the whole structure of the network gel is formed. Gelation time was calculated as the gel forming period and measured with a simple method of tilting with acetic acid after $\mathrm{pH}$ adjustment to 5.0. This parameter was taken as the time required for the reactant to avoid falling into the tilted tube position 6 .

Swelling Studies: Swelling studies included swelling time and swelling ratio.

Swelling Time: Swelling time is time taken by the hydrogel to reach its equilibrium swelling point where swelling is prevented. Swelling is usually measured gravimetrically and volumetrically a texture analyzer is used to assess swelling time. Dried SPH was allowed to hydrate more than swelling medium $(25 \mathrm{ml})$ at room temperature. At various time periods, the hydrogel was separated from the solution and measured after excess solvent on the surface was blotted.

Swelling Ratio: The swelling behavior of prepared SPH was carried out by the ' $\mathrm{T}$ ' bag weight method in which $0.1 \mathrm{~g}$ of sample was added to a small bag made of nylon $(50 \mathrm{~mm} \times 90 \mathrm{~mm}) 200 \mathrm{mesh}$. The bag was completely immersed in the swelling media $(200 \mathrm{ml})$ simulated gastric fluid $\mathrm{pH} 1.2$ at room temperature for $24 \mathrm{hrs}$ to each the swelling equilibrium. Adhered liquid droplets on the surface of samples were removed by blotting with tissue paper. The swollen SPH \& then dried in oven at $60^{\circ} \mathrm{C}$ for $6 \mathrm{hrs}$ until there was a no change in the weight of samples the equilibrium swelling was defined as follows. (Figure 1)

$$
\mathrm{Q}_{\mathrm{s}}=\frac{\mathrm{W}_{\mathrm{s}}-\mathrm{W}_{\mathrm{d}}}{\mathrm{W}_{\mathrm{d}}}
$$


Where, $W_{s}$ is the weight of the swollen superporous hydrogel, $\mathrm{W}_{\mathrm{d}}$ is the weight of the dried superporous hydrogel and $Q_{s}$ is equilibrium swelling ratio7.

Density Measurement: Dried SPHC was used for density measurements, which actually showed an apparent density of SPHC. A sample of SPHC was taken and weighed to evaluate the mass of the piece. A sample of the polymer was dipped into a predetermined volume of hexane in a graduated cylinder and the rise in hexane volume was measured as the volume of the polymer. Density was calculated by

$$
\text { Density }=\frac{\mathrm{M}_{\mathrm{SPHC}}}{\mathrm{V}_{\mathrm{SPHC}}}
$$

Where, $\mathrm{V}_{\text {SPHC }}$ is the volume of the solvent displaced by SPHC, MSPHC is the mass of the SPHC 8

Porosity Measurement: The solvent replacement process has been used for porosity measurement. The dried hydrogels were absorbed overnight in absolute ethanol and weighed after unwanted ethanol on the surface was blotted. The porosity of the following equation was calculated.

$$
\text { Porosity }=\frac{\mathrm{M} 2-\mathrm{M} 1}{\rho^{\mathrm{V}}}
$$

Where, M1 and M2 are the mass of the hydrogel before and after absorbed in absolute ethanol, $\rho$ is the density of absolute ethanol and $\mathrm{V}$ is the volume of the hydrogel 9 .

Measurement of Void Fraction: By immersion of the hydrogels into $\mathrm{HCl}$ (pH 1.2) buffer upto equilibrium swelling, the void fraction was identified inside superporous hydrogels. The dimensions of the swollen hydrogels were measured and the sample volumes were determined as dimensional volumes by using these data. Meanwhile, the amount of buffer absorbed in the hydrogels was determined by removing the weight of the dry hydrogel from the weight of the hydrogel swollen, the resulting values were assigned as the total volume of pores in the hydrogels. Void fraction calculated by following formula ${ }^{10}$ (Table 4 )

$$
\text { Void fraction }=\frac{\text { Dimensional volume of the hydrogel }}{\text { Total volume of pores }}
$$

Water Retention: Water retention capacity $\left(\mathrm{W}_{\mathrm{rt}}\right)$ as a function of time at $37^{\circ} \mathrm{C}$, was used to determine the following formula.

$$
\mathrm{W}_{\mathrm{rt}}=\frac{\mathrm{W}_{\mathrm{p}}-\mathrm{W}_{\mathrm{d}}}{\mathrm{W}_{\mathrm{s}}-\mathrm{W}_{\mathrm{d}}}
$$

Where, $W_{d}$ is the weight of dried hydrogel, Ws is the weight of fully swollen hydrogel and Wp is weights of the hydrogel at various exposure times ${ }^{11}$. (Table 5)

\section{Characterization of tablets}

The formulated tablets were evaluated for following parameters

\section{Pre Compressional Parameter:}

Angle of Repose: The angle of repose of the granules was determined by using the funnel method suggested by Neumann. The accurately weighed granules were taken in a funnel. The funnel height was raised to the point of the top of the granule heap. This funnel height was changed. The granules were allowed to flow freely to the surface through the funnel. The powder cone diameter has been determined, and the angle of repose was calculated by using the following formula,

$$
\Theta=\tan ^{-1} \mathrm{~h} / \mathrm{r}
$$

Bulk Density: Bulk density is the ratio of mass and bulk volume. Accurately weighed $20 \mathrm{~g}$ granules were allowed to flow in a fine stream into a graduated cylinder and final volume was noted.

$$
\text { Bulk density }=\frac{\text { Bulk mass }}{\text { Bulk volume }}
$$

Tapped Density: The 20gm blend into a graduated cylinder of a mechanical tapping instrument was permitted in the fine stream. The measuring cylinder was tapped for 100 times, and final tapped volume was measured. Tapped density formula was calculated by,

$$
\text { Tapped density }=\frac{\text { Bulk mass }}{\text { Tapped volume }}
$$

Carr's Index: Carr's index evaluates interparticulate cohesive characteristics with the angle of repose measurements and studies the effects of bulk- tapped solid packing geometry.

$$
\text { Carr's index }=\frac{\text { Tapped density }- \text { Bulk density }}{\text { Bulk density }} \times 100
$$

Hausner's Ratio: Hausner's ratio is a simple method to evaluate the stability of the powder column and to estimate flow properties. Hausner's ratio was calculated using formula. (Table 6)

$$
\text { Hausner's Ratio }=\frac{\text { Tapped density }}{\text { Bulk density }} \times 100
$$

\section{Post Compressional Parameter:}

Tablet thickness: Thickness and diameter of tablets were important for uniformity of tablet size. Thickness and diameter were measured using Vernier caliper.

Hardness: The hardness test was calculated by taking 6 tablets of every formulation and adding the strength to the tablet by using Monsanto hardness tester.

Friability: Friability test was performed by using Roche friabilator. The 20 tablets were weighed separately and placed in the drum that revolves at $25 \mathrm{r} / \mathrm{min}$ dropping the tablets through a distance of six inches with each revolution. After $4 \mathrm{~min}$ the tablets were weighed, and the percentage loss in tablet weight was calculated by using formula,

$$
\% \text { Loss }=\frac{\mathrm{W}_{\mathrm{O}}-\mathrm{W}_{\mathrm{f}}}{\mathrm{W}_{\mathrm{f}}} \times 100
$$

Where, $W_{0}$ is the initial weight of tablets and $W_{f}$ is finals weight of tablets.

Weight uniformity: 20 tablets were previously punched and measured there on a digital weighing balance. After that each tablet were weighed. The weight of a tablet was determined by our collective weight

\section{Content of Uniformity:}

The drug content is considered to check dose uniformity in the formulation. Total 20 tablets were weighed and powdered. The stock solution was prepared by dissolving a drug powder equivalent to $10 \mathrm{mg}$ in $10 \mathrm{ml}$ water. The stock solution was shaken on a sonicator for 20 minutes.

This resultant solution was further diluted with water to attain concentration upto $10 \mu \mathrm{g} / \mathrm{ml}$ and the absorbance was measured at $286 \mathrm{~nm}$. (Table 7).

\section{In-vitro Dissolution Study:}

The in-vitro dissolution study was performed by using USP apparatus type II at $37^{\circ} \mathrm{C} \pm 0.5^{\circ} \mathrm{C}$ using $900 \mathrm{ml}$ hydrochloric 
acid buffer (pH-1.2) as a dissolution medium at $50 \mathrm{r} / \mathrm{min}$. $5 \mathrm{ml}$ samples were withdrawn and replaced by new dissolution media at predetermined time intervals. The dissolution was continued the apparatus was allowed to the 12 hours the graphs of time vs percentage release were plotted. Withdrawn samples was filtered through a $0.45 \mu \mathrm{m}$ membrane filter, diluted and assayed at $286 \mathrm{~nm}$ using a UVVIS spectrophotometer. Cumulative percentage drug release was calculated by using an equation obtained from a calibration curve. To ascertain the order and mechanism of drug release the in-vitro release data was subjected to various kinetic equations.

\section{Kinetic Models}

\section{Treatment of dissolution data with different kinetic} equations:

In order to consider the mechanism of release and release rate kinetics of the dosage form, the data attain were fitted into Zero order, First order, Higuchi matrix, and Korsmeyer and Peppas. Based on the r-value, the best-fit model selected.

\section{Zero Order Kinetics:}

Zero-order release would be concluded by the given formula:

$$
\frac{\mathrm{dQ}}{\mathrm{dt}}=\mathrm{K}_{0}
$$

Where, $Q=$ Drug released at time ' $t$ '

$\mathrm{K}_{0}=$ Zero-order rate constant $(\mathrm{h}-1)$.

When the data is plotted as cumulative percent drug released vs time, if the plot is linear then the data obeys zero-order release kinetics, with a slope equal to $\mathrm{K}_{0}$.

\section{First Order Kinetics:}

To study the first order release rate kinetics, the release rate data were fitted to the given formula:

$$
\frac{\mathrm{dQ}}{\mathrm{dt}}=\mathrm{K}_{1} \mathrm{Q}
$$

Where, $Q=$ Amount of drug remained at time' $t$ '

$\mathrm{K}_{1}=$ First-order rate constant (h-1).

When the data is plotted as log cumulative percent drug remaining versus time; yields a straight line, indicating that the release follows first-order kinetics. The constant ' $\mathrm{K}_{1}$ ' can be obtained by multiplying 2.303 with slope values.

\section{Higuchi model:}

Higuchi developed several hypothetical models to study the release of water soluble and low soluble drugs incorporated in semisolids and/or solid matrices. Mathematical expressions were obtained for drug particles dispersed in a uniform matrix behaving as the diffusion media. And the given equation is,

$$
\mathrm{Qt}=\mathrm{KH} \mathrm{t}^{1 / 2}
$$

Where, $\mathrm{Qt}=$ amount of drug released in time $\mathrm{t}$,

$\mathrm{KH}=$ Higuchi dissolution constant

\section{Korsmeyer and Peppas model:}

The release rate from sustained release polymeric matrices can be described by the equation proposed by korsmeyer et al.

$$
\mathrm{Q}=\mathrm{K}_{\mathrm{KP}} \mathrm{tn}
$$

Where, $\mathrm{Q}=$ amount of drug released at time' $\mathrm{t}$ '
$\mathrm{K}_{\mathrm{KP}}=$ Kinetic constant incorporating structural and geometric characteristics of the tablets

' $n$ ' = The diffusional exponent, indicative of the release mechanism.

The release exponent, $n$, is the slope of log fraction of drug release vs log time cure. (Table 8) (Figure 2)

\section{Stability Studies:}

Stability studies on promising formulation were carried out in compliance with ICH guidelines by storing tablets at $40^{\circ} \mathrm{C}$ /75\% relative humidity for 3 months.

The sample was withdrawn at fixed time intervals of 0 (initial), 30, 60 and 90 days. At the end of three months, the time interval the tablets were tested for any hardness, changes in drug content, physical changes, and in-vitro dissolution studies. (Table 9) (figure 3).

\section{Compatibility Studies:}

\section{Fourier Transform Infrared (FT-IR) Spectroscopic Studies}

The compatibility between the pure nitazoxanide and SPH \& combination of nitazoxanide + PVA and pure PVA was tested by using FT-IR spectroscopy. The chemical structure of the synthesized hydrogels was also studied. The FTIR spectrum was recorded and the range of $400-4000 \mathrm{~cm}-1$ using $\mathrm{KBr}$ pellet method. (Figure 4)

\section{Differential Scanning Calorimetry Studies (DSC)}

The DSC was carried out for pure drug, tablet using a SHIMADZU DSC-60 plus differential scanning calorimeter. The system was calibrated with a high purity sample of nitazoxanide. Sample was scanned at the heating rate of $10^{\circ} \mathrm{C} / \mathrm{min}$ over a temperature range of 50 to $250^{\circ} \mathrm{C}$ under nitrogen gas using aluminum pans. (Figure 5)

Evaluation of Anthelmintic activity using Pheretima posthuma: Take 12 petridishes containing $10 \mathrm{ml}$ of sample in each petridish. Four groups were taken.

In group-I three petridishes were taken. In each petridish $10 \mathrm{ml}$ of saline solution was poured and one Pheretima posthuma was placed.

In group-II three petridishes were taken. In each petridish $10 \mathrm{ml}$ of metronidazole as a standard solution was poured and one Pheretima posthuma was placed.

In group-III three petridishes were taken. In each petridish $10 \mathrm{ml}$ of NSPH-I (nitazoxanide loaded superporous hydrogel) solution was poured and one Pheretima posthuma was placed.

In group IV three petridishes were taken. In each petridish $10 \mathrm{ml}$ of NSPH-II solution was poured and one Pheretima posthuma was placed. Observations were recored for (Table $10)$ the time taken for paralysis and time taken for death in minute. (Figure 6)

\section{Optimized $2^{3}$ Factorial design}

To classify the most important factors among all the factors, selection is done at beginning of the experimental procedure. From the experimental results, the effects of all studied variables and the variable interactions were graphically and statistically interpreted for all responses. The optimized nitazoxanide loaded SPH was used for the preparation of tablets. (Table 11)

The application of factorial design yielded the following regression equation. 
Cumulative $\%$ drug release $=$

$-113.50333+99.20833 \times$ Chitosan+38.75000 $\times$ PVA+1254.5000 $\times$ MCC.

Where, negative values indicate a negative effect of a specific variable on the response factor and positive value indicates positive effect of a specific variable. The polynomial regression result was expressed using 3D graph and contour plot. (Figure 7)

The ANOVA studies indicated that all models were significant $(\mathrm{p}<0.05)$ for all response parameters scrutinized. Model simplification was done by removing non-significant terms $(\mathrm{p}>0.05)$ in polynomial equations. (table.12)

Table 1: Formulation of Superporous Hydrogels

\begin{tabular}{|c|l|l|l|l|l|l|l|l|l|l|}
\hline \multirow{2}{*}{ Ingredients (mg) } & \multicolumn{9}{|c|}{ Formulation } \\
\cline { 2 - 11 } & I & II & III & IV & V & VI & VII & VIII & IX & X \\
\hline Chitosan (2\% W/V) & 40 & 80 & 120 & 160 & 80 & 80 & 80 & 80 & 80 & 80 \\
\hline Polyvinyl alcohol (10\% W/V) & 400 & 400 & 400 & 400 & 200 & 200 & 400 & 400 & 400 & 800 \\
\hline Formaldehyde (10\% V/V) & 400 & 400 & 400 & 400 & 400 & 400 & 400 & 200 & 600 & 800 \\
\hline Sodium bicarbonate & 80 & 80 & 80 & 80 & 80 & 80 & 80 & 80 & 80 & 80 \\
\hline Nitazoxanide & 500 & 500 & 500 & 500 & 500 & 500 & 500 & 500 & 500 & 500 \\
\hline
\end{tabular}

Table 2: Formulation of SPH tablets of Nitazoxanide

\begin{tabular}{|c|c|c|c|c|c|c|c|c|c|c|}
\hline \multirow[b]{2}{*}{ Ingredients (mg) } & \multicolumn{10}{|c|}{ Formulation } \\
\hline & I & II & III & IV & $\mathbf{V}$ & VI & VII & VIII & IX & $\mathbf{X}$ \\
\hline Nitazoxanide & 500 & 500 & 500 & 500 & 500 & 500 & 500 & 500 & 500 & 500 \\
\hline $\begin{array}{c}\text { Microcrystalline } \\
\text { cellulose }\end{array}$ & 61.32 & 72.83 & 81.7 & 65.17 & 49.39 & 52.27 & 69.59 & 49.59 & 58.5 & 86.7 \\
\hline Sodium bicarbonate & 16 & 16 & 16 & 16 & 16 & 16 & 16 & 16 & 16 & 16 \\
\hline Magnesium stearate & 4 & 4 & 4 & 4 & 4 & 4 & 4 & 4 & 4 & 4 \\
\hline Talc & 2 & 2 & 2 & 2 & 2 & 2 & 2 & 2 & 2 & 2 \\
\hline
\end{tabular}

Table 3: Variables in $2^{3}$ Factorial Design

\begin{tabular}{|c|c|c|}
\hline \multirow{2}{*}{ Independent Variable } & Low & High \\
\cline { 2 - 3 } & $0.04 \%$ & $0.16 \%$ \\
\hline A: Chitosan & $0.2 \%$ & $0.8 \%$ \\
\hline B: PVA & $0.09 \%$ & $0.12 \%$ \\
\hline C: MCC & Dependent Variable \\
\hline \multicolumn{2}{|c|}{ Cumulative \% drug release } \\
\hline
\end{tabular}

Table 4: Characterization of superporous hydrogels

\begin{tabular}{|c|c|c|c|c|c|c|c|c|}
\hline \multirow{2}{*}{$\begin{array}{l}\text { Batch } \\
\text { code }\end{array}$} & \multicolumn{8}{|c|}{ Parameters } \\
\hline & $\begin{array}{l}\text { Percent } \\
\text { Yield (\%) }\end{array}$ & $\begin{array}{c}\text { Drug } \\
\text { content }(\%)\end{array}$ & $\begin{array}{c}\text { Gelation } \\
\text { time (sec) }\end{array}$ & $\begin{array}{l}\text { Swelling } \\
\text { time (min) }\end{array}$ & $\begin{array}{l}\text { Swelling } \\
\text { ratio }\end{array}$ & $\begin{array}{c}\text { Density } \\
\text { (g/cc) }\end{array}$ & $\begin{array}{c}\text { Porosity } \\
\text { (\%) }\end{array}$ & $\begin{array}{c}\text { Void } \\
\text { fraction } \\
(\%)\end{array}$ \\
\hline 1 & $20.45 \pm 0.11$ & $84.54 \pm 0.01$ & $31.22 \pm 0.54$ & $5.01 \pm 0.02$ & $103.33 \pm 5.15$ & $0.49 \pm 0.02$ & $3.65 \pm 0.22$ & $5.75 \pm 1.88$ \\
\hline 2 & $18.23 \pm 0.15$ & $95.46 \pm 0.56$ & $35.12 \pm 0.86$ & $5.00 \pm 0.01$ & $120.25 \pm 2.98$ & $0.51 \pm 0.03$ & $5.20 \pm 0.16$ & $4.01 \pm 0.31$ \\
\hline 3 & $15.46 \pm 0.42$ & $104.80 \pm 0.01$ & $29.56 \pm 0.01$ & $5.12 \pm 0.03$ & $140.20 \pm 2.88$ & $0.23 \pm 0.01$ & $8.25 \pm 0.30$ & $3.77 \pm 0.20$ \\
\hline 4 & $12.33 \pm 0.20$ & $108.45 \pm 0.01$ & $14.52 \pm 0.54$ & $5.19 \pm 0.01$ & $182.66 \pm 7.98$ & $0.26 \pm 0.01$ & $9.23 \pm 0.23$ & $3.45 \pm 0.35$ \\
\hline 5 & $21.50 \pm 0.21$ & $75.48 \pm 0.20$ & $22.10 \pm 1.02$ & $5.02 \pm 0.01$ & $118.66 \pm 4.98$ & $0.49 \pm 0.00$ & $18.25 \pm 0.25$ & $3.75 \pm 0.38$ \\
\hline 6 & $14.28 \pm 0.19$ & $80.75 \pm 0.25$ & $20.16 \pm 0.89$ & $4.56 \pm 0.04$ & $105.45 \pm 0.06$ & $0.35 \pm 0.00$ & $30.24 \pm 3.02$ & $2.75 \pm 0.25$ \\
\hline 7 & $13.20 \pm 0.43$ & $90.20 \pm 0.01$ & $16.45 \pm 1.35$ & $5.00 \pm 0.00$ & $55.44 \pm 5.12$ & $0.30 \pm 0.02$ & $29.13 \pm 0.05$ & $1.99 \pm 0.15$ \\
\hline 8 & $10.25 \pm 0.30$ & $76.25 \pm 0.01$ & $80.66 \pm 1.25$ & $4.88 \pm 0.19$ & $83.65 \pm 5.02$ & $0.25 \pm 0.00$ & $24.52 \pm 0.02$ & $2.58 \pm 0.14$ \\
\hline 9 & $15.55 \pm 0.56$ & $85.13 \pm 0.01$ & $91.00 \pm 0.01$ & $5.09 \pm 0.15$ & $25.55 \pm 2.22$ & $0.30 \pm 0.02$ & $3412 \pm 4.44$ & $1.45 \pm 0.02$ \\
\hline 10 & $25.79 \pm 0.33$ & $89.51 \pm 0.01$ & $192.22 \pm 2.5$ & $5.00 \pm 0.01$ & $20.00 \pm 5.20$ & $0.35 \pm 0.01$ & $40.11 \pm 0.20$ & $1.89 \pm 0.14$ \\
\hline
\end{tabular}


Table 5: Water Retention capacity

\begin{tabular}{|c|c|c|}
\hline S.NO. & Time & Water retention capacity \\
\hline $\mathbf{1}$ & 0 & 0.9 \\
\hline $\mathbf{2}$ & 3 & 0.75 \\
\hline $\mathbf{3}$ & 6 & 0.82 \\
\hline $\mathbf{4}$ & 9 & 0.85 \\
\hline $\mathbf{5}$ & 12 & 0.92 \\
\hline $\mathbf{6}$ & 15 & 0.87 \\
\hline $\mathbf{7}$ & 18 & 0.84 \\
\hline $\mathbf{8}$ & 21 & 0.87 \\
\hline $\mathbf{9}$ & 24 & 0.84 \\
\hline
\end{tabular}

Table 6: Precompressional parameters of SPH tablets

\begin{tabular}{|c|c|c|c|c|c|}
\hline \multirow{2}{*}{$\begin{array}{l}\text { Batch } \\
\text { code }\end{array}$} & \multicolumn{5}{|c|}{ Precompressional parameters } \\
\hline & $\begin{array}{c}\text { Bulk density } \\
\left(\mathrm{g} / \mathrm{cm}^{3}\right)\end{array}$ & Tapped density $\left(\mathrm{g} / \mathrm{cm}^{3}\right)$ & $\begin{array}{c}\text { Carr's index } \\
(\%)\end{array}$ & Hauner's ratio & $\begin{array}{l}\text { Angle of } \\
\text { repose }\left({ }^{\circ}\right)\end{array}$ \\
\hline 1 & $0.23 \pm 0.0012$ & $0.25 \pm 0.0080$ & $8.00 \pm 0.26$ & $1.08 \pm 0.032$ & $22.30 \pm 1.22$ \\
\hline 2 & $0.25 \pm 0.0093$ & $0.30 \pm 0.00$ & $16.66 \pm 2.25$ & $1.2 \pm 0.035$ & $26.40 \pm 5.24$ \\
\hline 3 & $0.26 \pm 0.0075$ & $029 \pm 0.016$ & $10.34 \pm 4.55$ & $1.11 \pm 0.06$ & $30.20 \pm 1.20$ \\
\hline 4 & $0.18 \pm 0.0042$ & $0.25 \pm 0.042$ & $25.00 \pm 2.24$ & $1.38 \pm 0.05$ & $28.31 \pm 1.60$ \\
\hline 5 & $0.59 \pm 0.014$ & $0.80 \pm 0.089$ & $26.25 \pm 6.25$ & $1.35 \pm 0.08$ & $20.15 \pm 3.25$ \\
\hline 6 & $0.48 \pm 0.026$ & $0.59 \pm 0.040$ & $18.64 \pm 8.45$ & $1.22 \pm 0.10$ & $19.00 \pm 1.25$ \\
\hline 7 & $0.45 \pm 0.021$ & $0.50 \pm 0.58$ & $10.02 \pm 0.32$ & $1.11 \pm 0.05$ & $22.14 \pm 2.20$ \\
\hline 8 & $0.40 \pm 0.020$ & $0.45 \pm 0.25$ & $11.11 \pm 7.45$ & $1.12 \pm 0.04$ & $30.25 \pm 1.46$ \\
\hline 9 & $0.20 \pm 0.001$ & $0.23 \pm 0.0035$ & $13.05 \pm 1.26$ & $1.15 \pm 0.02$ & $18.42 \pm 1.25$ \\
\hline 10 & $0.30 \pm 0.00$ & $0.35 \pm 0.015$ & $14.28 \pm 2.05$ & $1.16 \pm 0.05$ & $25.21 \pm 1.41$ \\
\hline
\end{tabular}

Table 7: Post compressional parameters of SPH tablets

\begin{tabular}{|c|c|c|c|c|c|c|c|}
\hline \multirow{2}{*}{$\begin{array}{c}\text { Batch } \\
\text { code }\end{array}$} & \multicolumn{7}{|c|}{ Post Compressional parameters } \\
\cline { 2 - 8 } & $\begin{array}{c}\text { Weight } \\
\text { variation (\%) }\end{array}$ & $\begin{array}{c}\text { Diameter } \\
\mathbf{( m m )}\end{array}$ & $\begin{array}{c}\text { Thickness } \\
\mathbf{( m m )}\end{array}$ & $\begin{array}{c}\text { Hardness } \\
\left(\mathbf{g} / \mathbf{c m}^{2}\right)\end{array}$ & $\begin{array}{c}\text { Friability } \\
\mathbf{( \% )}\end{array}$ & $\begin{array}{c}\text { Disintegration } \\
\text { time (min) }\end{array}$ & $\begin{array}{c}\text { Content } \\
\text { uniformity }\end{array}$ \\
\hline 1 & $0.25 \pm 0.246$ & $7.08 \pm 0.005$ & $2.75 \pm 0.000$ & $4.45 \pm 0.055$ & 0.224 & $28.44 \pm 1.51$ & $98.58 \pm 0.85$ \\
\hline 2 & $0.22 \pm 0.244$ & $7.05 \pm 0.004$ & $2.74 \pm 0.001$ & $4.44 \pm 0.052$ & 0.122 & $29.22 \pm 1.51$ & $98.52 \pm 0.55$ \\
\hline 3 & $0.19 \pm 0.22$ & $7.05 \pm 0.003$ & $2.74 \pm 0.003$ & $4.40 \pm 0.051$ & 0.225 & $36.00 \pm 1.00$ & $99.71 \pm 083$ \\
\hline 4 & $0.23 \pm 0.210$ & $7.08 \pm 0.000$ & $2.74 \pm 0.000$ & $4.42 \pm 0.050$ & 0.250 & $30.00 \pm 0.55$ & $99.99 \pm 0.25$ \\
\hline 5 & $0.25 \pm 0.21$ & $7.04 \pm 0.001$ & $2.74 \pm 0.005$ & $4.45 \pm 0.053$ & 0.228 & $40.12 \pm 0.57$ & $100.0 \pm 0.74$ \\
\hline 6 & $0.26 \pm 0.19$ & $7.04 \pm 0.005$ & $2.74 \pm 0.004$ & $4.40 \pm 0.056$ & 0.200 & $27.66 \pm 0.57$ & $99.97 \pm 0.50$ \\
\hline 7 & $0.27 \pm 0.20$ & $7.05 \pm 0.000$ & $2.74 \pm 0.000$ & $4.44 \pm 0.053$ & 0.220 & $35.22 \pm 0.55$ & $98.98 \pm 0.85$ \\
\hline 8 & $0.18 \pm 0.23$ & $7.04 \pm 0.002$ & $2.74 \pm 0.001$ & $4.43 \pm 0.054$ & 0.224 & $33.25 \pm 0.54$ & $97.58 \pm 0.88$ \\
\hline 9 & $0.25 \pm 0.21$ & $7.05 \pm 0.005$ & $2.74 \pm 0.002$ & $4.40 \pm 0.051$ & 0.222 & $31.55 \pm 1.24$ & $99.58 \pm 0.77$ \\
\hline 10 & $0.24 \pm 0.26$ & $7.05 \pm 0.000$ & $2.74 \pm 0.000$ & $4.41 \pm 0.050$ & 0.244 & $34.25 \pm 0.45$ & $100.1 \pm 0.64$ \\
\hline
\end{tabular}


Table 8: Drug release kinetics of optimized formulations

\begin{tabular}{|c|c|c|c|c|c|c|c|c|c|c|}
\hline Batch no & F1 & F2 & F3 & F4 & F5 & F6 & F7 & F8 & F9 & F10 \\
\hline $\begin{array}{l}\text { Model } \\
\text { name }\end{array}$ & $\mathbf{R}^{2}$ & $\mathbf{R}^{2}$ & $\mathbf{R}^{2}$ & $\mathbf{R}^{2}$ & $\mathbf{R}^{2}$ & $\mathbf{R}^{2}$ & $\mathbf{R}^{2}$ & $\mathbf{R}^{2}$ & $\mathbf{R}^{2}$ & $\mathbf{R}^{2}$ \\
\hline Zero Order & 0.7599 & 0.7044 & 0.8541 & 0.7872 & 0.776 & 0.8361 & 0.8377 & 0.8391 & 0.8189 & 0.8083 \\
\hline First Order & 0.784 & 0.7296 & 0.8734 & 0.8185 & 0.8081 & 0.8657 & 0.8696 & 0.87 & 0.8523 & 0.8422 \\
\hline $\begin{array}{l}\text { Higuchi } \\
\text { mode }\end{array}$ & 0.9289 & 0.8971 & 0.9254 & 0.9369 & 0.9255 & 0.9505 & 0.9685 & 0.9541 & 0.9628 & 0.9548 \\
\hline $\begin{array}{l}\text { Kor's } \\
\text { peppas }\end{array}$ & 0.4759 & 0.4206 & 0.4944 & 0.4702 & 0.4477 & 0.5081 & 0.5499 & 0.5175 & 0.5315 & 0.512 \\
\hline
\end{tabular}

Table 9: Drug content data of stability studies

\begin{tabular}{|c|c|c|c|c|}
\hline Time & 90days & 60days & 30days & 0days \\
\hline 10000 & 89.26 & 89.3 & 89.43 & 89.72 \\
\hline 20000 & 90 & 90.02 & 90.05 & 90.08 \\
\hline 30000 & 94.16 & 94.27 & 94.38 & 94.48 \\
\hline 40000 & 93.05 & 93.17 & 93.21 & 93.29 \\
\hline 50000 & 97.81 & 97.88 & 98 & 98.03 \\
\hline 60000 & 93.66 & 93.75 & 93.86 & 93.97 \\
\hline 70000 & 95.55 & 95.65 & 95.79 & 95.87 \\
\hline 80000 & 94.14 & 94.26 & 94.38 & 94.49 \\
\hline 90000 & 98.33 & 98.42 & 98.53 & 98.66 \\
\hline 100000 & 99.24 & 99.32 & 99.41 & 99.52 \\
\hline
\end{tabular}

Table 10: Antihelminthic activity of Nitazoxanide loaded SPH

\begin{tabular}{|c|c|c|c|}
\hline $\begin{array}{c}\text { Name of the } \\
\text { group }\end{array}$ & Treatment group & $\begin{array}{c}\text { Sample } \\
\text { concentration }\end{array}$ & $\begin{array}{c}\text { Time taken for paralysis } \\
\text { in minutes }\end{array}$ \\
\hline Group -I & Vehicle (Saline) & $0.9 \% \mathrm{Nacl}$ & - \\
\hline Group -II & Metronidazole & $400 \mathrm{mg} / \mathrm{ml}$ & 30 \\
\hline Group -III & NSPH -I & $200 \mathrm{mg} / \mathrm{ml}$ & 75 \\
\hline Group -IV & NSPH -II & $400 \mathrm{mg} / \mathrm{ml}$ & 55 \\
\hline
\end{tabular}

Table 11: Observed response in $2^{3}$ factorial design for formulation f10

\begin{tabular}{|c|c|c|c|c|c|}
\hline \multirow{2}{*}{ Std. } & \multirow{2}{*}{ Run } & Factor 1 & Factor 2 & Factor 3 & Response \\
\cline { 2 - 5 } & & A:Chitosan & B:PVA & C:MCC & Cumulative \% drug release \\
\hline 6 & 1 & 0.16 & 0.2 & 0.12 & 29.51 \\
\hline 3 & 2 & 0.04 & 0.8 & 0.09 & 74.67 \\
\hline 7 & 3 & 0.04 & 0.8 & 0.12 & 25.07 \\
\hline 1 & 4 & 0.04 & 0.2 & 0.09 & 32.86 \\
\hline 4 & 5 & 0.16 & 0.8 & 0.09 & 27.35 \\
\hline 2 & 6 & 0.16 & 0.2 & 0.09 & 37.00 \\
\hline 5 & 7 & 0.04 & 0.2 & 0.12 & 99.52 \\
\hline 8 & 8 & 0.16 & 0.8 & 0.12 & \\
\hline
\end{tabular}


Table 12: ANOVA for selected factorial model response of $\%$ cumulative drug release

\begin{tabular}{|c|c|c|c|c|c|}
\hline Source & Sum of Squares & df & Mean square & F-value & P-value \\
\hline Model & 4197.37 & 3 & 1399.12 & 6.60 & 0.0499 \\
\hline A-chitosan & 283.4 & 1 & 283.46 & 1.34 & 0.3120 \\
\hline B-PVA & 1081.12 & 1 & 1081.12 & 5.10 & 0.0869 \\
\hline C-MCC & 2832.79 & 1 & 2832.79 & 13.36 & 0.0217 \\
\hline Residual & 848.35 & 4 & 212.09 & & \\
\hline
\end{tabular}
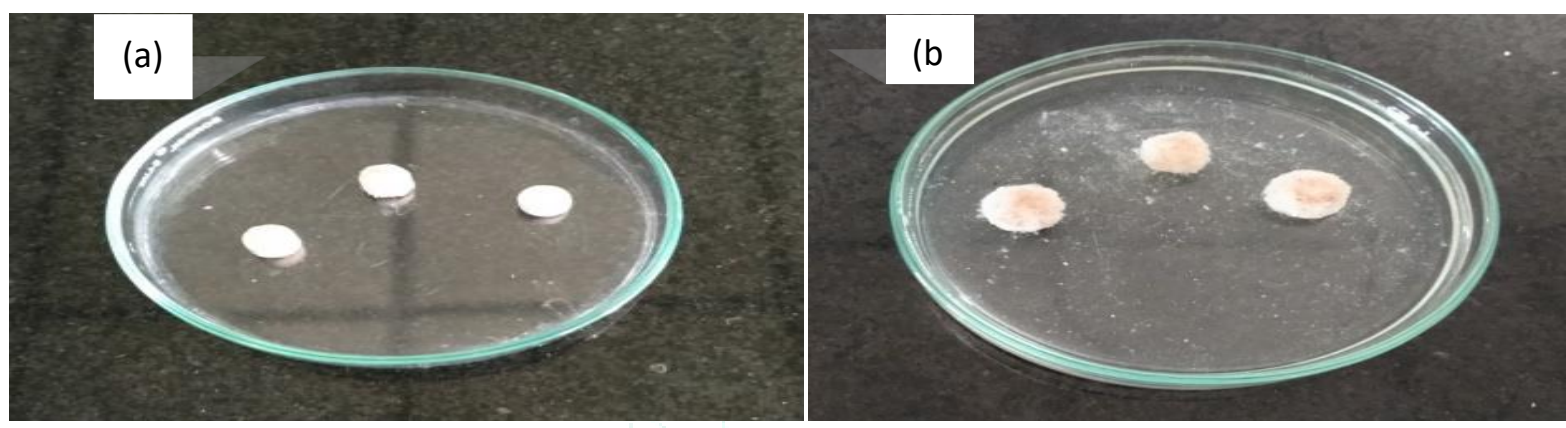

Figure 1: (a) Before swelling, (b) After swelling

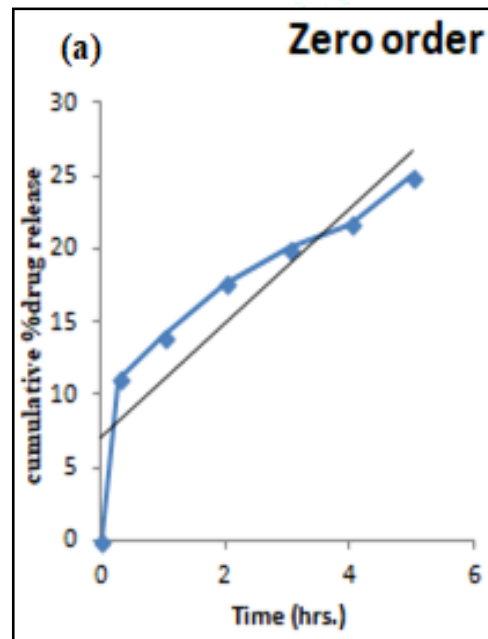

(b)

$y=3.9457 x+7.0345$

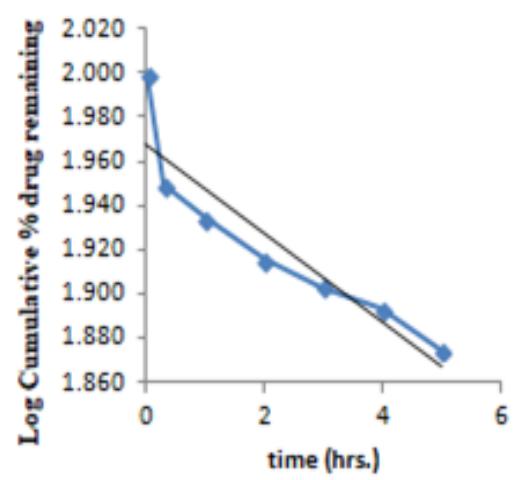

$y=-0.0201 x+1.9682$

$R^{2}=0.8083$

$\leadsto$ Zeroorder

- Linear (Zero orde

(c) Higuchi

(d)

Kors-peppas
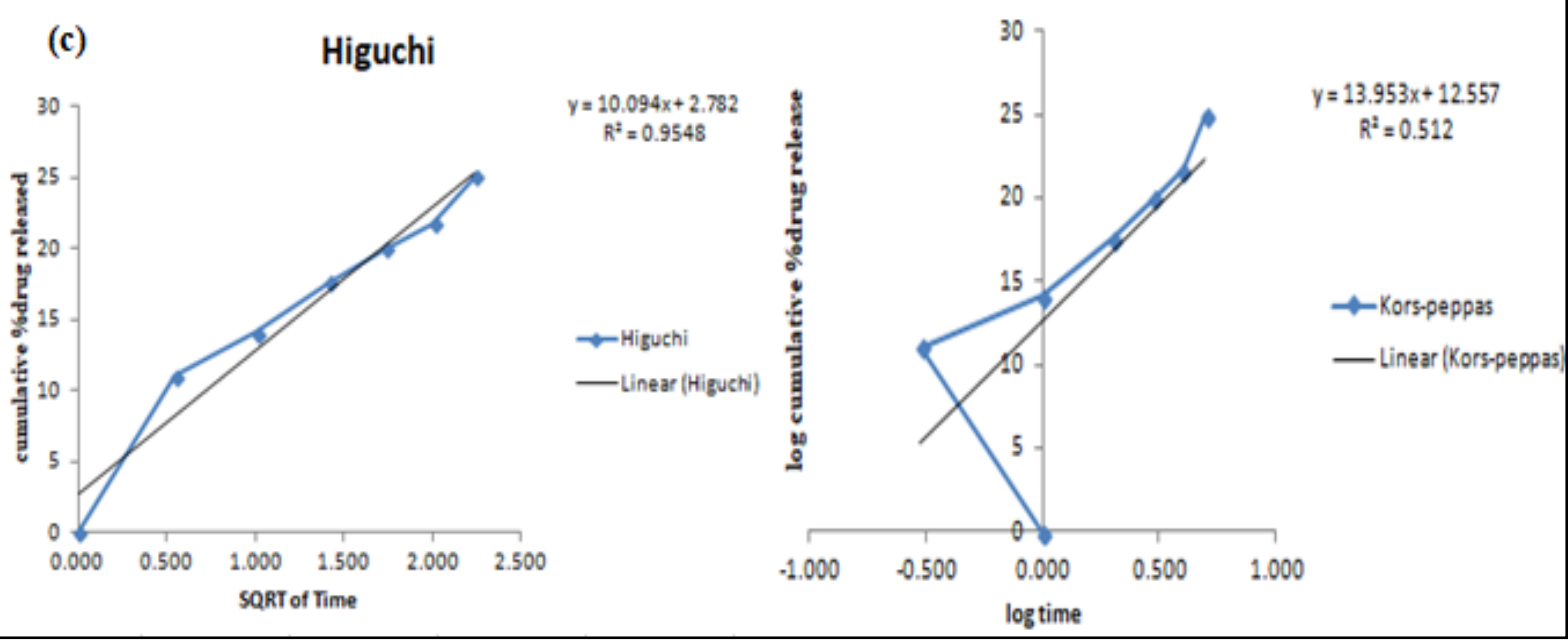

Figure 2: Drug release kinetic models for (a) zero order (b) first order (c) higuchi plot (d) kors-peppas 


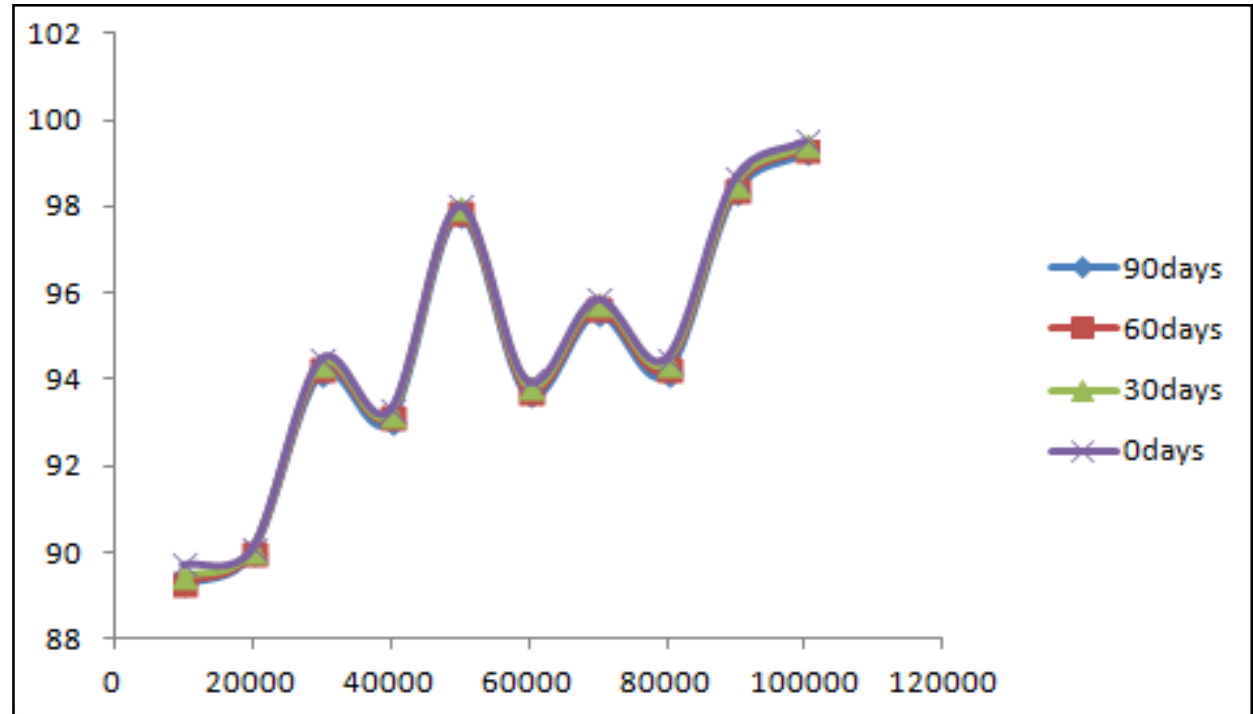

Figure 3: Dissolution profile of stability studies

(a)
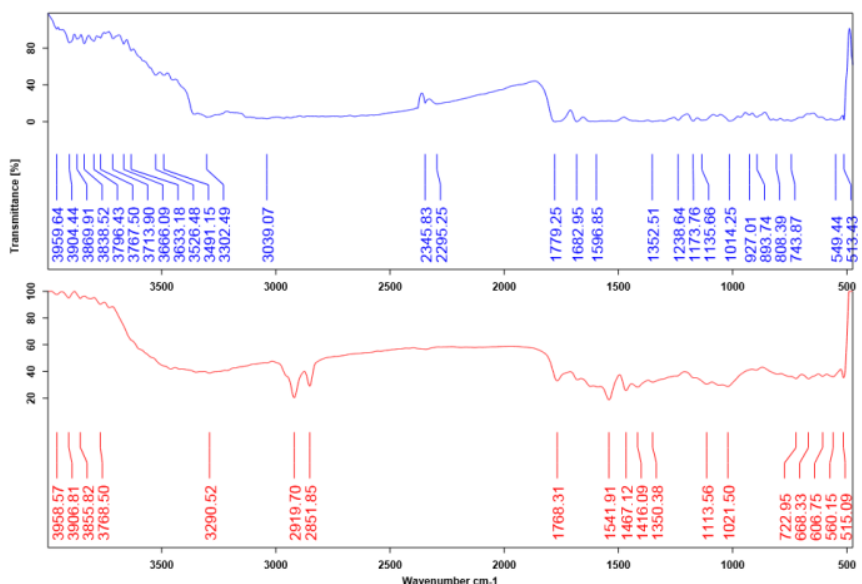

(b)

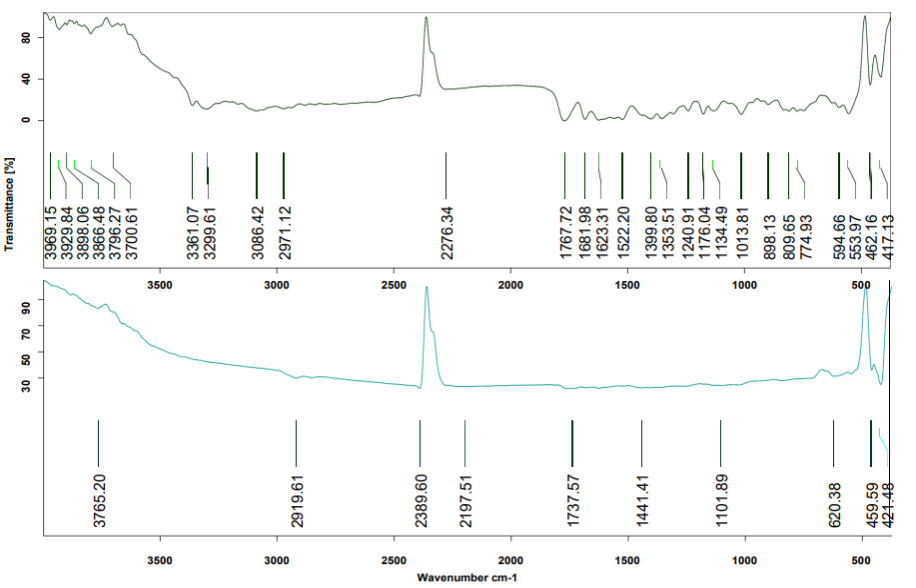

Figure 4: Comparison of FTIR study of nitazoxanide (a) Pure nitazoxanide and SPH, 
(a)

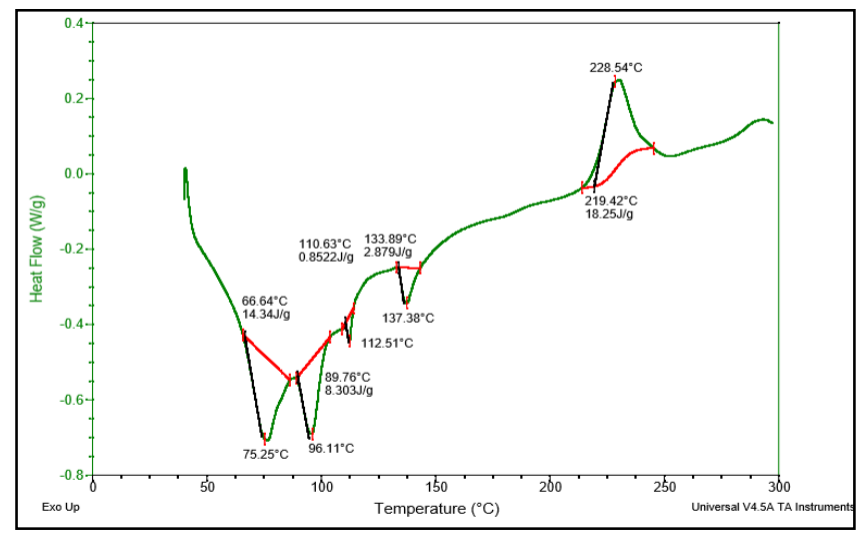

(b)

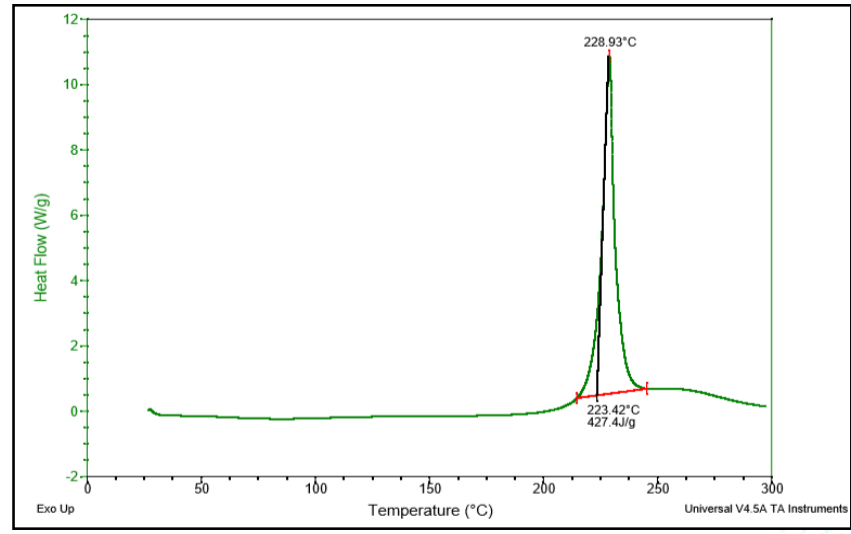

Figure 5: DSC graphs for (a) nitazoxanide loaded SPH tablet (b) Pure Nitazoxanide

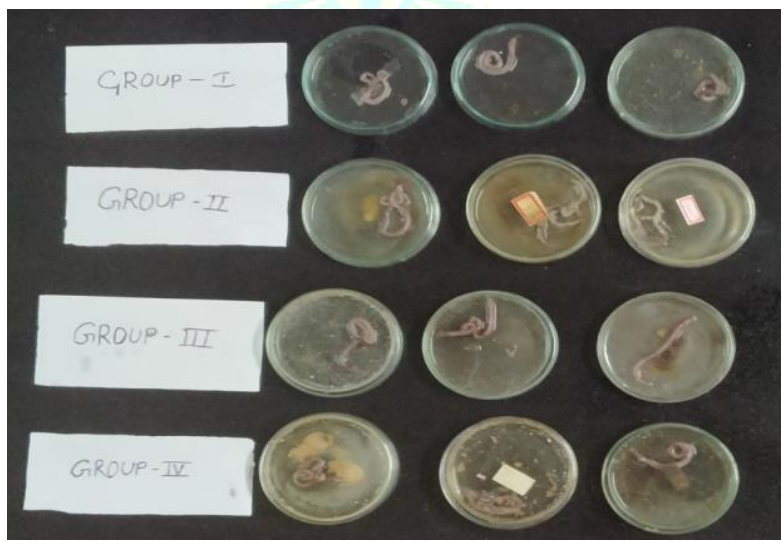

Figure 6: Antihelminthic activity-time of paralysis testing of SPH tablets in Pheretima posthuma
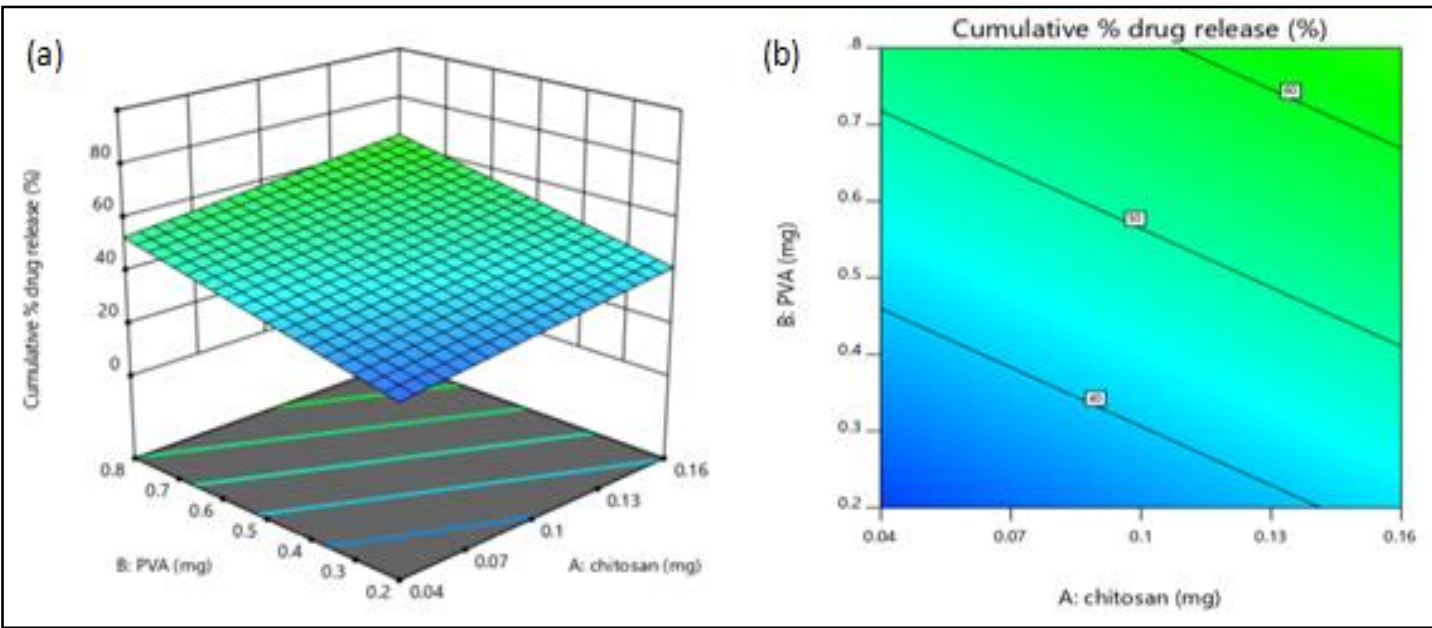

Figure 7: DOE Plots for (a) 3D Surface plot (b) Contour plot 


\section{CONCLUSION}

This study discusses the preparation of nitazoxanide loaded superporous hydrogel tablets. The superporous hydrogel tablets of nitazoxanide were prepared by direct compression method. This study is mainly based on chitosan and used as a carrier. The SPH tablets of nitazoxanide showed good precompressional, post-compressional properties and better invitro drug release profiles are showed in this work. FI-IR and DSC studies showed that the drug was compatible with SPHC particles. The formulation F10 prepared by direct compression containing SPH tablets of nitazoxanide were optimized by using $2^{3}$ factorial design and prepared by cross linking technique exhibited good swelling index as well as maximum rate of drug release. So, finally all formulations were successfully formulated. This study also demonstrates that superporous hydrogel tablets may be suitable for use as a gastro-retentive drug delivery system.

\section{ACKNOWLEDGEMENT}

The authors are thankful to Principal, Department of pharmaceutical Sciences, Chalapathi Institute of pharmaceutical sciences for providing facilities to successfully complete our research work.

\section{REFERENCES:}

[1] Gupta V, Shiva Kumar H.G, "Preparation and Characterization of Superporous Hydrogels as $\mathrm{pH}$ Sensitive Drug Delivery System for Pantoprazole Sodium". Curr drug deliv 2009; 6(1):505-510.

[2] Chavda H, Patel C, "Chitosan superporous hydrogel compositebased floating delivery system: A newer formulation approach". J Pharm Bioall Sci 2010; 2(2):124-131.
[3] Chen J, Blevins WE, Haesunpark., Park K, "Gastric retention properties of superporous hydrogel composites". J control release 2000; 64 (1-3): 39-51.

[4] Sapana P., Ahirrao., Rathi KS, Koli DB, Kshirsagar SJ, Pawar S, "Solubility Enhancement of nitazoxanide using solid dispersion". Ind Res J Pharm \& Sci 2018; 5 (4):1674-1687.

[5] Patil-Vibhute, P.B., Hajare, A.A, "Preparation and characterization of Superporous Hydrogels as gastroretentive drug delivery system for Atenolol" Int. J. Pharm. Sci 2019; 10 (1):272-285.

[6] Swamy SK, NGN, "Development and Evaluation of superporous Hydrogels for metoprolol Tartrate as a gastro retentive system". IJNDD 2012; 4 (2):104-109.

[7] Bollaram M, Maheshwar rao UM, "Formulation and in-vitro evaluation of gastroretentive superporous hydrogel tablets of Phenylephrine". Int. j. innov 2015; 3(1):59-71.

[8] Prasanna Kumar Desu., P., Venkateswara Rao, Vijay Kotra. "Synthesis and characterization of PVA Based Poly (Acrylic acid Coacrylamide) superporous hydrogels composites". Int. J. Pharm. Sci. Res 2018; 9 (10):4361-4367.

[9] Pati NB, Velivela S, Mayasa V, Gupta VRM, “Gastroretentive superporous hydrogel tablets of dexlansoprazole". Int. J. Pharm. Sci. Res 2016; 7(11):4678-4685.

[10] Bhalla S, Nagpal M, "Comparison of various generations of superporous hydrogels based on Chitosan-Acrylamide and Invitro drug release" ISRN Pharmaceutics. 2013; 1(3):234-242

[11] Sushma P, Vishnu P, Maheshwar Rao VU, Naveen Babu K, “ Formulation and In-vitro evaluation of gastro-retentive superporous hydrogel tablets of famotidine" Indo Am. j. pharm 2015; 5(10):3191-3202. 